\title{
Author Correction: Dietary Additives and Supplements Revisited: the Fewer, the Safer for Gut and Liver Health
}

\author{
Rachel M. Golonka ${ }^{1} \cdot$ Beng San Yeoh ${ }^{2} \cdot$ Matam Vijay-Kumar ${ }^{1,3}$ (I)
}

Published online: 1 July 2019

(C) Springer Nature Switzerland AG 2019

\section{Author Correction: Current Pharmacology Reports https://doi.org/10.1007/s40495-019-00187-4}

The original version of this article contained a mistake. The statement "VSL\#3 (commercialized as Visbiome®)" is not correct. VSL\#3 ${ }^{\circledR}$ is not commercialized under the brand Visbiome ${ }^{\circledR}$. It is currently available in the market with the same brand and is being sold in more than 30 countries. VSL\#3 $®$ is the proper labeling of the product.

The authors apologize for this oversight and for any confusion it may have caused.

Publisher's Note Springer Nature remains neutral with regard to jurisdictional claims in published maps and institutional affiliations.

The online version of the original article can be found at https://oi.org/ 10.1007/s40495-019-00187-4

Matam Vijay-Kumar

MatamVijay.Kumar@Utoledo.edu

1 Department of Physiology \& Pharmacology, University of Toledo College of Medicine and Life Sciences, Toledo, OH 43614, USA

2 Graduate Program in Immunology \& Infectious Disease, Pennsylvania State University, University Park, PA 16802, USA

3 Department of Medical Microbiology \& Immunology, University of Toledo College of Medicine and Life Sciences, Toledo, OH 43614, USA 